\title{
A FORMAÇÃO DE PROFESSORES NA/PARA EDUCAÇÃO BÁSICA: PONTOS E CONTRAPONTOS.
}

\author{
Francieli Lara Rodrigues Pinto Ferreira \\ Marcelo Máximo Purificação
}

Universidade Estadual do Mato Grosso Sul - UEMS

Centro Universitário de Mineiros - UNIFIMES

\begin{abstract}
Resumo: Este artigo aborda a questão da formação de professores na rede de ensino fundamental. A formação adequada serve como base para a construção de escolas, cidadãos e profissionais competentes, éticos e humanos. Neste contexto, a escola tem um papel crucial para o desenvolvimento no desenvolvimento de crítico e no aperfeiçoamento das técnicas de formação contínua de professores, na promoção de uma articulação entre professor-aluno e aluno / aluno. Nossos dias atuais, muitos alunos não sentem atraídos ao aprendizado, essa por sinal, é uma tarefa difícil, mas, que precisa ser levada em consideração pelos sistemas de ensino. Por isso, é interessante trazer a discussão sobre os exemplos de práticas para o cenário de formação de professores, no intuito de gerar reflexões e novas práticas.
\end{abstract}

Palavras-chave: Professor; formação; aluno; aprendizado

\section{TEACHER TRAINING IN / FOR BASIC EDUCATION: POINTS AND COUNTERPOINTS}

\begin{abstract}
This article addresses the issue of teacher training in the elementary school network. Adequate training serves as a basis for building competent, ethical and human schools, citizens and professionals. In this context, the school has a crucial role for the development in the development of critic and in the improvement of the techniques of continuous training of teachers, in the promotion of an articulation between teacher-student and student / student. Nowadays, many students are not attracted to learning, this by the way, is a difficult task, but one that needs to be taken into account by the education systems. Therefore, it is interesting to bring the discussion about the examples of practices to the scenario of teacher training, in order to generate reflections and new practices.
\end{abstract}

Key words: Teacher; formation; student; learning

Como citar o artigo: FERREIRA. Francieli Lara Rodrigues Pinto. PURIFICAÇÃO, Marcelo Máximo. A formação de professores na/para a educação básica: pontos e contrapontos. Revista Científica Novas Configurações-Diálogos Plurais, v. 2 n. 1, 2021

\section{INTRODUÇÃO}

O que pode ser definido como formação profissional?

A definição de formação profissional consiste num conjunto de atividades que visam transmitir os conhecimentos, competências e atitudes necessárias à aquisição dos conhecimentos práticos e teóricos

Fonte de financiamento: Nenhum

Conflito de interesse: Os autores declaram não haver Nenhum conflito de interesse.

E-mail do autor-correspondência: francielilara@outlook.com

Data de recebido: 22/10/2020

Data de aprovado: 05/12/2020

Editora: Elisângela Maura Catarino. 


\section{A FORMAÇÃO DE PROFESSORES NA/PARA A EDUCAÇÃO BÁSICA: PONTOS E CONTRAPONTOS}

responsáveis pelo bom desempenho de um indivíduo no seu local de trabalho e na carreira em geral (IBCCOACHING, 2018).

O indivíduo com formação profissional pretende formar pessoas não só em conhecimentos técnicos e práticos, mas também em conhecimentos éticos, políticos, sociais e comportamentais, entre outros, para que tenham uma visão ampla do mundo e dos problemas relacionados com a construção de uma sociedade democrática melhor e mais eficiente (IBCCOACHING, 2018).

Tendo em conta o conceito acima evocado, podemos dizer que a formação contínua é algo contínuo com encontros que acompanham o desenvolvimento do professor e a presença de um formador que conhece a realidade da escola e da escola e do aluno. A implementação é feita em duplas, sendo a prática diária aprofundada e refletida com encontros regulares que acompanham a presença do professor. Isso deve ser feito preferencialmente no local de trabalho, ou seja, durante a carga horária do professor, com espaço físico de estudo e treinamento garantido.

“Assim, para atender às novas demandas sociais, os cursos de Formação de professores vêm fazendo constantes ajustes em seus projetos pedagógicos. A última alteração se deu em função das Resoluções CNE. $n^{\circ}$. 02 de 2015/2019 que estabeleceu novas regras e diretrizes para a formação de professores no Brasil”, afirmam PURIFICAÇÃO et al. (2020, p, 201).

Para garantir que os professores se alinhem com a Base Curricular Comum Nacional (BNCC), eles devem ter o suporte e as ferramentas para aproximá-los nas práticas durante o seu trabalho através de encontros entre pares na mesma área de conhecimento. (RESOLUÇÃO, $n^{\circ}$ 02/2019). A partir dessa prerrogativa, que vem sendo falada também em outros artefatos legais, trazemos, à luz do Artigo 62 da LDB (Lei de Diretrizes e Bases da Educação Nacional) informações basilares para formação docente:

\footnotetext{
Art. 62. A formação de docentes para atuar na educação básica far-se-á em nível superior, em curso de licenciatura plena, admitida, como formação mínima para o exercício do magistério na educação infantil e nos cinco primeiros anos do ensino fundamental, a oferecida em nível médio, na modalidade normal.

$\S 2^{\circ}$ A formação continuada e a capacitação dos profissionais de magistério poderão utilizar recursos e tecnologias de educação à distância.
}

De acordo com a LDB, a educação básica compreende a educação pré-escolar, o ensino fundamental e o ensino médio, a fim de garantir a todo cidadão o direito de concluir seus estudos básicos e, portanto, de prosseguir seus estudos no nível superior.

Existem muitas maneiras de se tornar um professor. Para ser professor de pré-escola e ensino fundamental ( $1^{\mathrm{a}}$ a $5^{\mathrm{a}}$ série), é necessário ter licenciatura em Pedagogia ou segunda licenciatura, ou formação pedagógica. Para atuar na segunda fase do Ensino Fundamental II ( $6^{\mathrm{a}}$ a $9^{\mathrm{a}}$ série $)$ e no Ensino Médio é necessária licenciatura em área específica. Também poderão se habilitar por meio de Complementação Pedagógica, graduados em nível de bacharelado e tecnólogos, desde que atendidas às exigências especificadas na Resolução no $02 / 2019$.

\section{Desenvolvimento}




\section{A FORMAÇÃO DE PROFESSORES NA/PARA A EDUCAÇÃO BÁSICA: PONTOS E CONTRAPONTOS}

Este artigo trata da formação de professores do ensino fundamental que, no mundo atual, tem levantado uma série de questionamentos sobre o papel profissional do professor e proposto uma redefinição. A análise do papel desses profissionais buscou premiar novas ideias sobre educação, os últimos conceitos de desenvolvimento e aprendizagem. Com o advento da tecnologia, a informação e a comunicação sobre os processos de ensino e aprendizagem contribuíram para esse exame. A necessidade de metodologias, técnicas e materiais de apoio mais recentes também é uma fonte de inspiração.

Na linha dessas ideias, Freire (1996) esclarece que:

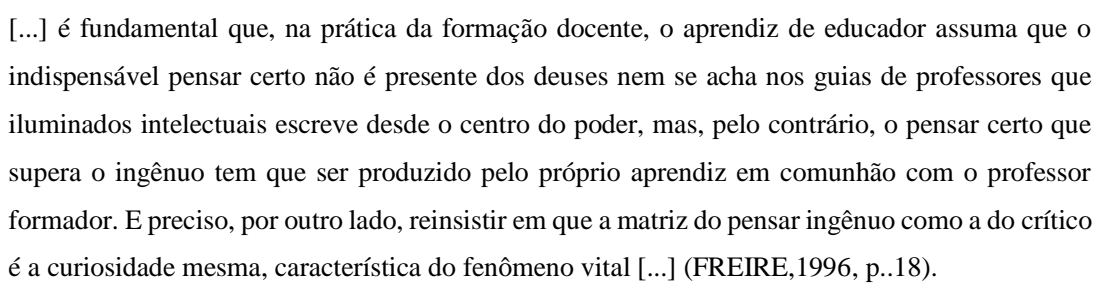

No momento em que um professor se torna investigativo e desafiador e consegue provocar a autonomia dos alunos, estimulando a criatividade e a habilidade dos outros, ele pode se tornar um cidadão pensante, desafiador e crítico. É extremamente importante que o educador esteja ciente de que o aluno pensante tem um papel fundamental a desempenhar em sua própria educação. Parte disso é criação, pesquisa, estudo e questionamento. O professor que o encorajou deve agora responder a questões, ajudar a compreender, fazer e formar cidadãos pensantes, criativos e independentes.

É interessante pensar, que no atual contexto, o processo de ensino e aprendizagem acontece de forma integrada. Por isso, o professor que outrora foi visto como centro do processo, assume a mediação desse processo. Para que essa mediação seja satisfatória, é preciso ter uma visão ampla de todos os elementos que permeiam o processo de aprendizagem, sejam eles internos (dentro da escola) e externos (do contexto social). Para além disso, o professor nesse novo cenário, precisa tornar suas aulas diferenciadas, dinâmicas e sempre pensando no aluno e na construção de sua autonomia didática. De forma metafórica Rubem Alves (1994), discute essa questão. O fragmento de sua fala, citamos abaixo:

[...] Poderá haver sofrimento maior para uma criança ou um adolescente que ser forçado a moverse numa floresta de informações que ele não consegue compreender, e que nenhuma relação parece ter com sua vida? Compreende-se que, com o passar do tempo a inteligência se encolha por medo e horror diante dos desafios intelectuais, e que o aluno passe a se considerar como um burro. Quando a verdade é outra: a sua inteligência foi intimidada pelos professores e, por isto, ficou paralisada. [...] (ALVES, RUBEM, 1994, p. 16-17).

Partindo do especificado por Rubem Alves e sua metáfora, compreende-se que a motivação é um dos postulados mais poderosos para o processo de ensino aprendizagem. Professores motivados, vão além do rasamente planejado para suas aulas. Usam de forma pedagógica artefatos diversos, no intuito de aproximar o aluno do conhecimento, nesse rol de artefatos, as tecnologias têm grandes contribuições.

Vista a partir da perspectiva do aluno, a motivação colabora no rompimento do medo. Medo pensar, de se posicionar, de acertar e de errar. O processo de aprendizagem torna-se muito mais significativo, quando essa 


\section{A FORMAÇÃO DE PROFESSORES NA/PARA A EDUCAÇÃO BÁSICA: PONTOS E CONTRAPONTOS}

barreira é inexistente. Motivados, os alunos vão além do esperado, buscam o conhecimento em vários contextos, intercruzando -os a saberes e reais situações do seu dia a dia. No final desse processo, o aluno sente-se apto a intervir nesses contextos, pensando sobre possíveis soluções para os problemas que se tornaram objeto de seus estudos.

Pensando a partir da perspectiva metafórica de Rubem Alves, temos ingredientes de sobra para pensarmos nos elementos que colaboram e constituem nossa identidade docentes, assim como nos elementos colaboram para construção identitária de nosso alunado.

Diante de tal fato, Coracini (2002), especifica que:

(...) a identidade do professor, de um modo geral, é constituída pelo desejo de autonomia e de poder. Assim sendo, o professor, como representante 'oficial' da instituição escola, tem funcionado como um elemento inibidor, tudo direcionando, tudo moldando... (cf. Coracini, 2002).

Coracini (2000) argumenta que para entender o que está acontecendo em sala de aula, é necessário atentar para as regularidades que caracterizam as posições dos objetos que se apoiam no imaginário. Assim, a postura do professor é questionada pela identidade do professor que ocupa o lugar de saber-poder, e seu discurso está impregnado de um discurso jurídico que concretiza a relação entre direitos e deveres. Ou seja, é o professor que sabe o que é melhor para os alunos, como devem aprender, o que aprender ou o que dizer em determinadas situações; enfim, aquele que sempre é responsável pela avaliação, julgamento, supervisão e punição (cf. Foucault, 1987). Mais tarde, Coracini (2000, p. 191) conclui:

Faz parte da identidade do sujeito-professor não ter dúvidas, mas apenas certezas, não problematizar o ensino e a aprendizagem, mediante a problematização do sujeito, mas de alguma maneira, buscar 'soluções', imediatas, se possível, aos problemas relacionados ao ensino e à aprendizagem, ainda que, para isso seja necessário simplificá-los ao extremo.

Portanto, para que a função do aluno como personagem principal seja efetiva, é necessário que haja um professor com funções que vão além da transferência de conteúdos específicos. O educador deve conhecer e se adaptar à realidade moderna, os interesses, qualidades e habilidades dessa modernização do aluno. É importante ouvir o aluno, respeitar o seu ponto de vista, realizar atividades de investigação do conhecimento estimulantes e construtivas, apresentar aulas inovadoras e construtivas, e que o aluno procure este conhecimento de forma diversa, diminuindo assim, a lacuna entre o ensino e a aprendizagem.

A educação deve ser concebida como a criação de sujeitos autônomos, o compartilhamento da experiência e da razão e a contribuição para a autonomia, onde o aluno pode expressar o seu pensamento e ter liberdade de decisão. Aplicar conhecimentos na vida social e utilizar esses conhecimentos nas situações do quotidiano para resolver problemas, tomar consciência dos valores das suas ações, saber lidar com os conflitos quotidianos.

O objetivo de valorizar o pensamento crítico não é criar indivíduos egoístas, desobedientes e autossuficientes, mas sim que os indivíduos que podem compreender a base das regras estejam abertos à comunicação, às ideias e às mudanças pelas quais passaram durante o processo de aprendizagem na escola e na vida. 


\section{A FORMAÇÃO DE PROFESSORES NA/PARA A EDUCAÇÃO BÁSICA: PONTOS E CONTRAPONTOS}

Portanto, é extremamente importante que o professor seja um mediador na busca de conhecimentos que colabore com o processo de aprender, debater, confrontar ideias, estimular a curiosidade, a vontade e a reflexão. Por isso, é importante adotar métodos que desenvolvam a autonomia do aluno sem seguir, onde o professor não seja mais o único detentor do conhecimento, mas, um mediador de processo que constrói o ensino por meio de práticas inovadores, dialógicas onde a toca de conhecimento seja constante.

\section{CONSIDERAÇÕES FINAIS}

Ao analisar a estrutura de financiamento da educação, devemos pensar que se trata de um elemento estruturante para a organização e operacionalização das políticas públicas educacionais, portanto, para a materialização do sistema educacional nacional. A educação é um direito fundamental que contribui não só para o desenvolvimento de um país, mas também de todas as pessoas.

A escola deve ser repensada como um direito universal e abrangente de todos, incluindo todos os cidadãos. Para isso, a contribuição da escola e do professor tem papel fundamental, para que a educação integral seja efetiva.

Em conclusão, a formação contínua de professores é o processo de aperfeiçoamento dos conhecimentos necessários à atividade docente, que se realiza ao longo da vida profissional com o objetivo de assegurar uma ação pedagógica eficaz que promova uma aprendizagem significativa, mas para isso o professor deve receber estímulos, incentivos e valorização. A valorização deve ser um elemento balizador, pois, deve atender aos professores, demais servidores da educação, os alunos e seu grupos social.

Para que essas práticas ocorram em sala de aula, é necessário que o professor passe por um processo de aprimoramento contínuo dos conhecimentos necessários à atividade docente, a fim de contribuir para uma formação completa e promover uma aprendizagem significativa e efetiva. Responsabilidade essa, que deve iniciar nos sistemas educacionais por meio de políticas públicas educacionais.

Esse processo de aprimoramento deve passar pelo comprometimento do educador e também da administração escolar, articulando a prática com a teoria e enfatizando aqueles aspectos que traduzem a formação como algo positivo, tendo efeitos satisfatórios, pois a formação de professores desempenha um papel estratégico na qualidade da educação.

O objetivo da formação contínua é garantir que o conhecimento seja transmitido de forma complexa, considerando as diferentes formas de ensino e explicitando o mesmo conteúdo para que o aluno possa absorver o que foi transmitido em sala de aula. Juntando assim teoria e prática. Essa união torna-se fundamental para a busca integral por conhecimentos efetivos nas práticas de ensino, sendo este evento de extrema importância para um resultado efetivo e absoluto.

Por fim, os conhecimentos necessários à formação de professores e educadores são indiscutíveis para a melhoria contínua, bem como o desenvolvimento das competências e habilidades necessárias ao ensino e aprendizagem, demonstrando uma qualidade suprema de ensino em sala de aula. Para isso, o sistema educacional 


\section{A FORMAÇÃO DE PROFESSORES NA/PARA A EDUCAÇÃO BÁSICA: PONTOS E CONTRAPONTOS}

deve ser responsável por promover o desenvolvimento e crescimento profissional de seus professores, por meio da formação continuada, e a escola, responsável pelo processo de aprendizagem do aluno de forma significativa.

\section{Referências}

ALVES, Rubem. A ALEGRIA DE ENSINAR / Rubem Alves. ARS Poética Editora Ltda. 1994.

CORACINI, Maria José. "LÍNGUA ESTRANGEIRA E LÍNGUA MATERNA: UMA QUESTÃO DE SUJEITO E IDENTIDADE (1997)”. In Letras \& Letras, Uberlândia, MG, vol.14, no 1, p.153-169. (2000).

CORACINI, Maria José. “DISCURSO E SOCIEDADE”. Pelotas, EDUCAT. “A SUBJETIVIDADE NA ESCRITA DO PROFESSOR”. Campinas: Unicamp - IEL/DLA. (2002).

CORACINI, Maria José. “AUTONOMIA, PODER E IDENTIDADE NA SALA DE AULA”. In Linguística e Educação: Gramática, Discurso e Ensino. Oliveira \& Passegi [org.]. \& Pereira [orgs.]p.184 (2001).

FOUCAULT, Michel. MICROFÍSICA DO PODER. 23. ed. São Paulo: Graal, 2004.

FREIRE, Paulo. PEDAgOgIA DA AUTONOMIA: SABERES NECESSÁRIOS À PRÁtiCA EDUCATIVA / Paulo Freire. - São Paulo: Paz e Terra, 1996. - (Coleção Leitura).

GOUVEIA, Andréa Barbosa. A POLÍTICA DE FINANCIAMENTO DA EDUCAÇÃo BÁSICA. Jornal de Políticas Educacionais. Vol. 01, n. 01. Pág. 75-79. Março 2007.

Lei $\mathbf{n}^{\text {o }} \mathbf{9 . 3 9 4}$ de 20 de Dezembro de 1996 . Disponível em <https://www.jusbrasil.com.br/topicos/11686325/artigo-62-da-lei-n-9394-de-20-de-dezembro-de-1996> Acesso em: 23 de junho de 2020.

IBCCOACHING. Afinal, o que pode ser definido como formação profissional? Postado em 29 de novembro de 2018 por Equipe IBC Disponível em> https://www.ibccoaching.com.br/portal/afinal-o-que-pode-serdefinido-como-formacao-profissional/. Acesso em 20 set de 2020.

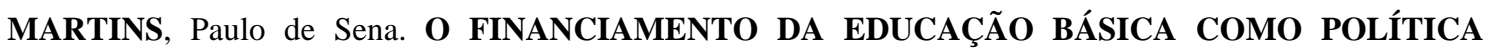
PÚBLICA. RBPAE. Vol. 26, n. 03. Pág. 497-514. Set/Dez. 2010.

PURIFICAÇÃO, Marcelo Máximo; Catarino, Elisângela Maura; Teixeira, Maria Filomena Rodrigues; Santana, Lousana de Jesus; Abdalla, Cláudia de Souza; Alves, Angélica Ferreira (2020). Curriculum and Identity its Impacts on the School Context in Goiás: Points and Counterpoints. Am. In. Mult. J., Jul to Oct. (9) 5, 196204.

Informações sobre os autores:

FLRPF: Possui graduação em Ciências Físicas e Biológicas pela Fundação Educacional de Fernandópolis (2016). Atualmente é professor de ciências e biologia na rede estadual de São Paulo e professora PEB II na escola municipal EMEF "Angelo Scarin" na disciplina de Ciências. Graduada em Pedagogia.Pó-graduada em Psicopedagogia Institucional e Clinica e Educação Especial com enfase em Deficiência Intelectual. Cursou a disciplina Linguagem, Discurso eEnsino em 2019 como aluna especial na UEMS. Cursando como aluna especial no programa de 


\section{A FORMAÇÃO DE PROFESSORES NA/PARA A EDUCAÇÃO BÁSICA: PONTOS E CONTRAPONTOS}

Mestrado acadêmico da UEMS - Universidade Estadual de Mato Grosso do Sul na disciplina "Tópicos Especiais em Currículo, Formação Docente e Diversidade: Formação de Professores da Contemporaneidade: interseções entre o campo teórica e as políticas educacionais". Email: janieli.ferreira1@enova.educacao.ba.gov.br

MMP: Pós-Doutor em Educação pela Universidade de Coimbra - Portugal. Doutor em Ciências da Religião pela PUC-Goiás (2014). Graduado em Matemática, Pedagogia e Filosofia. Professor permanente do mestrado em educação da Universidade Estadual do Mato Grosso do Sul UEMS. E-mail: maximo@unifimes.edu.br

Contribuições dos autores: (FLRPF; MMP) conceitualização, captação de recursos, supervisão, redação. 